\title{
Research Paper: Obsessive-Compulsive Tendencies \& Self-Concept Clarity Among Females With and Without Hormonal Imbalance
}

\author{
Yaqoob Nazia $^{1 *}$ (D) Zahid Ambreen ${ }^{1}$ (D) \\ 1. Department of Applied Psychology, Faculty of Government, Women University, Faisalabad, Pakistan.
}

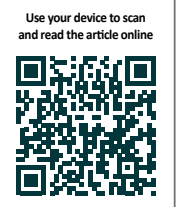

Citation Nazia Y, Ambreen Z. Obsessive-Compulsive Tendencies \& Self-Concept Clarity Among Females With and Without Hormonal Imbalance. Journal of Research \& Health. 2021; 11(5):297-304. http://dx.doi.org/10.32598/JRH.11.5.1916.1

http://dx.doi.org/10.32598/JRH.11.5.1916.1

\section{(i) (3)}

Article info:

Received: 19 Jun 2021

Accepted: 31 Jul 2021

Publish: 01 Oct 2021

\section{Keywords:}

Obsessive Compulsive Tendencies, Self-Concept Clarity, Hormonal Imbalance

\begin{abstract}
Background: The role of hormones in the female body is well known in reproductive age. Several studies have been conducted regarding hormonal fluctuations and their association with obsessive-compulsive disorder, but the role of psychological issues relevant to it has been ignored and only hormonal fluctuation and its impact were the target. Thus, the main purpose of this study was to examine the relationship between Self-Concept Clarity (SCC) and obsessive-compulsive tendencies (Obsessive-Compulsive Concerns about Cleanliness (OCC) and Obsessive-Compulsive concerns about Harm and Injury (OCHI)). Another objective was to identify the difference between SCC, OCC, and OCHI in healthy and unhealthy females.

Methods: A sample of $(\mathrm{N}=210)$ females, an equal number of healthy and unhealthy females, from different hospitals and the general population, with a mean age of 21 years, was selected by using convenience sampling technique as a type of non-probability sampling. Study participants were selected from the same city.

Results: Comparison of healthy and unhealthy females revealed high levels of SCC and obsessive-compulsive tendencies among unhealthy females and also a significant positive correlation was found between these constructs.

Conclusion: The females with irregular hormonal fluctuations develop obsessive-compulsive tendencies and these people are most sensitive to unimportant affairs, even sensitive to themselves that might create clarity in their self-concept.
\end{abstract}

\footnotetext{
"Corresponding Author:

Nazia Yaqoob

Address: Department of Applied Psychology, Faculty of Government, Women University, Faisalabad, Pakistan.

Phone: +92 (320) 3057455

E-mail: naziayaqoob@gcwuf.edu.pk
} 


\section{Introduction}

B

alance in the hormonal system of the body is necessary for mental and physical health as it facilitates the functioning of all other systems of the body in many ways [1]. A woman can suffer from hormonal imbalance at any stage of her life. Such imbalances create the possibility of many physical and mental health risks, such as depression, anxiety, nervous tension, memory problems, fatigue, high blood pressure, infertility, heart disease, etc. [2]. While considering all this, the current study was done to assess the levels of Self-Concept Clarity (SCC) and obsessive-compulsive tendencies (Obsessive-Compulsive concerns about Cleanliness (OCC) and Obsessive-Compulsive concerns about Harm and Injury (OCHI)) among females with hormonal imbalance.

An imbalance may occur in different hormones and can lead to many problems, such as high estrogen levels that can cause insomnia, hot flashes, and fatigue. Low testosterone and estrogen levels can be the cause of osteoporosis and heart problems. Endometrial cancer and high blood pressure can be developed due to low progesterone levels. A female with high testosterone levels may experience facial hair, acne, and aggression. It also has risks for endometrial and breast cancer and diabetes. There are many health risks associated with imbalanced ratios of estrogen, progesterone, and testosterone [2].

Our body has sensitive chemistry and any minor change in this chemistry creates noticeable symptoms. Insufficient sleep, high stress, thyroid problems, pregnancy, unhealthy lifestyle and diet, diabetes, and other conditions can cause hormonal imbalance. Infertility, endometriosis, and heavy periods are the major symptoms that can be seen in females with hormonal imbalance. Other systems of the body can also be affected by this [3].

Natural therapies, lifestyle changes, and taking medication may successfully treat hormonal imbalances. Bioidentical or synthetic hormones are prescribed mostly in medical treatment. It is called hormone replacement therapy. Bioidentical hormones are derived from a natural substance. Synthetic hormones are created to mimic the effects of natural hormones. Both types of hormone replacement therapy can be very effective at restoring balance and resolving symptoms [3].

Obsessive-Compulsive Disorder (OCD) is characterized by recurrent thoughts and repetitive behaviors that are uncontrollable. People with this disorder may experience symptoms related to obsession, compulsion, or both, such as thoughts related to germs and contamination, and actions related to recurrent washing and cleaning [4].

Obsessions, compulsions, and escaping approaches are thematically diverse in addition to replicating the person's vastly distinctive apprehensions. An individual may have obsessional doubts that he or she can be mistakenly treated as an uninspired person. This state drives the person feels obligatory to check the edge, additional strength have obsessional thoughts of a sexual nature leading to evading of situations and the use of psychological rites to counterbalance such "sinful" judgements and diminish the dread of penalty from God. Yet another individual might demonstrate all these signs in one occasion [5].

In general, the relationship between physical fitness, self-concept, and sexual functioning has been investigated [6]. The most recent study conducted on body dysmorphic disorder, in which a person is not satisfied with her physical appearance, showed that such person also has issues with their physical SCC. The study focused on treatment synthesis and consensus on behalf of the International College of Obsessive-Compulsive Spectrum Disorders and the Obsessive-Compulsive and Related Disorders Network of the European College of Neuropsychopharmacology [7].

A few studies are addressing OCD patients, such as Fox's Doctoral work in 2019 entitled "A look at the self, self-concept, and stigma resistance among those suffering from OCD" [8]. Another recent study reported prenatal sex hormones and finger length: Digit ratio (2D:4D) as a biological marker of early developmental processes in patients with OCD [9].

When a person knows who she is, has beliefs that are not conflicting, he has such opinions about the self that are constant over time, called high in SCC. When one's self-concept is clear, her knowledge about herself would be cognitively organized. SCC provides a person with a good sense of understanding that allows her to make good decisions about life and yield great well-being [10].

\section{The rationale of the study}

Hormonal imbalance among females is becoming common nowadays, but a very small portion of its psychological consequences can be found in the existing body of knowledge. Hence, there is a strong need to discover the psychological aspects of a woman's life that are being influenced badly by this disease. This study would yield either there is any relationship between hormonal imbalance and the development of OCD or not. A little 
work has already been done on the contribution of hormonal activity in OCD but it had done nothing to address the disease, but rather targeted hormonal fluctuation [11]. Besides, due to the expecting health risks of this disease, such as infertility, females may feel inferior and they may have an unclear concept of themselves. Such dimension has not been yet discovered. This study based on the quantitative method might be the first attempt to know all this.

\section{Objectives}

The study was done to assess obsessive-compulsive tendencies, SCC, and their relationship among females with and without hormonal imbalance. We also examined the differences between the females diagnosed with hormonal imbalance and healthy females regarding obsessive-compulsive tendencies (OCC and OCHI) and SCC.

\section{Methods}

This study was conducted after approval from the local Ethics Committee at the Government College Women University (No.GCWUF/A.Psy/17/170). A correlational research design was used to assess the relationship between the OCC, OCHI, and SCC among females with and without hormonal imbalance. The comparative research design was used to compare healthy and unhealthy females regarding OCC, OCHI, and SCC.

A convenient sampling technique was used to select the target sample. A sample of $(\mathrm{N}=210)$ females from different public and private hospitals and the general population, with an age ranging from 15 to 55 years, was taken. Female participants were further divided into the sub-samples of healthy $(n=105)$ and unhealthy $(n=105)$ females. Married and unmarried females with menstrual problems were included in the study.

SCC is defined as the extent to which an individual's specific self-beliefs are clearly and confidently defined, internally consistent, and temporally stable [12]. The
Self-Concept Clarity (SCC) scale developed by Campbell et al. is a unidimensional measure using a 5-point Likert scale item ranging from 1 strongly disagree to 5 strongly agree and the range of scale is from 12 to 60 . The coefficient alpha of internal consistency of this scale in this study was 0.83 (Table 1) [12].

The Dimensional Obsessive-Compulsive Scale (DOCS) contains 20 items and it is a self-report measure of four dimensions (contamination, responsibility, unacceptable thoughts, and symmetry) of obsessive-compulsive symptoms. It was developed by Abramowitz et al. and tested over 5 years (2005-2010) and has been translated into many languages as of January 2017 [7]. The DOCS contain 4 subscales. Each subscale contains 5 items, which are rated from 0 to 4 [13]. In the current study, two dimensions of DOCS were measured i.e. contamination (OCC) and Responsibility (OCHI). Demographic form used to measure demographic characteristics of the study participants (Table 2). Cronbach's alpha for OCC and $\mathrm{OCHI}$ was 0.84 and 0.87 , correspondingly (Table 1 ).

Measuring scales to measure SCC and obsessivecompulsive tendencies were taken from online websites. After obtaining permission from the authors, the scales were translated into Urdu to meet the compatibility of the targeted population. Then, a departmental approval letter was taken from the head of the department, and the collection of data was started from the patients in the gynecology ward of different hospitals and the general population of females. Participants who met the inclusion criteria were told about the purpose of the study and they were assured that their provided information would be kept confidential. Then they filled forms. SPSS v. 21 was used for data entry and data analysis. Descriptive statistics, Pearson productmoment coefficient correlation, and independent sample t-test were used to analyze data.

Table 1. Reliability index, item details, number of items, scoring range, cut-off scores, and mean values of subscales

\begin{tabular}{ccccccc}
\hline Name of Scale & Item Numbers in Scales & Scoring Range & Cut-off Scores & Mean & No of Items & Alpha \\
\hline SCC & $1-12$ & $12-60$ & $>30$ & 34.61 & 12 & 0.83 \\
OCC & $1-5$ & $0-20$ & $>9$ & 7.26 & 5 & 0.84 \\
OCHI & $1-5$ & $0-20$ & $>9$ & 8.34 & 5 & 0.87 \\
\hline
\end{tabular}

SCC: Self-Concept Clarity; OCC: Obsessive-Compulsive Concerns about Cleanliness; OCHI: Obsessive-Compulsive Concerns about Harm and Injury 


\section{Results}

The present study was conducted to assess the levels of and relationship between SCC, OCC, and OCHI among females with and without hormonal imbalance. Further differences regarding SCC, OCC, and OCHI among females with and without hormonal imbalance were also assessed. Pearson product-moment coefficient correlation was used to examine the correlation between SCC, OCC, and OCHI. An independent sample t-test was used to assess the differences regarding SCC, OCC, and OCHI among healthy and unhealthy females.

Table 2. Frequencies and percentages of demographic variables of healthy and unhealthy females $(n=210)$

\begin{tabular}{|c|c|c|c|}
\hline \multicolumn{3}{|c|}{ Variables } & No. (\%) \\
\hline \multirow{2}{*}{ Health status } & \multicolumn{2}{|r|}{ Healthy } & $105(50)$ \\
\hline & \multicolumn{2}{|r|}{ Unhealthy } & $105(50)$ \\
\hline \multirow{6}{*}{ Marital status } & \multirow{3}{*}{ Healthy } & Married & $12(11.4)$ \\
\hline & & & \\
\hline & & Unmarried & $93(88.6)$ \\
\hline & & & \\
\hline & \multirow{2}{*}{ Unhealthy } & IVrarnea & $49(40.7)$ \\
\hline & & Unmarried & $56(53.3)$ \\
\hline \multirow{7}{*}{ Family system } & \multirow{4}{*}{ Healthy } & Nuclear & $78(75.3)$ \\
\hline & & & \\
\hline & & Joint & $27(25.7)$ \\
\hline & & & \\
\hline & \multirow{3}{*}{ Unhealthy } & Nuclear & 69(65.7) \\
\hline & & & \\
\hline & & Joint & $36(34.3)$ \\
\hline \multirow{11}{*}{ Monthly income } & \multirow{6}{*}{ Healthy } & Less than 15000 & $3(2.9)$ \\
\hline & & Between $15-30$ thousand & $11(10.5)$ \\
\hline & & Between $30-50$ thousand & $49(46.7)$ \\
\hline & & Between $50-80$ thousand & $21(20)$ \\
\hline & & More than 80 thousand & $21(20)$ \\
\hline & & & C19 \\
\hline & \multirow{5}{*}{ Unhealthy } & Less than 15000 & $5(4.8)$ \\
\hline & & Between $15-30$ thousand & $5(3.8)$ \\
\hline & & Between $30-50$ thousand & $25(23.8)$ \\
\hline & & Between $50-80$ thousand & $26(24.8)$ \\
\hline & & More than 80 thousand & $45(42.5)$ \\
\hline \multirow{6}{*}{$\begin{array}{l}\text { Menstruation routine in Unhealthy } \\
\text { female }\end{array}$} & \multirow{3}{*}{ Regular } & Yes & $37(35.2)$ \\
\hline & & & \\
\hline & & No & $68(63.8)$ \\
\hline & \multirow{3}{*}{ Skip } & Yes & $38(36.2)$ \\
\hline & & & \\
\hline & & No & $67(63.8)$ \\
\hline \multirow{2}{*}{ Facial hair in unhealthy female } & & Yes & $36(34.3)$ \\
\hline & & $\mathrm{No}$ & $69(657)$ \\
\hline
\end{tabular}


Table 3. Correlation between SCC, OCC, and OCHI among unhealthy and healthy females $(n=210)$

\begin{tabular}{cccc}
\hline \multicolumn{1}{c}{ Variables } & & OCC & OCHI \\
\hline All females & SCC & $0.47^{* *}$ & $0.45^{* *}$ \\
& OCC & 1 & $0.74^{* *}$ \\
Healthy females & SCC & $0.33^{* *}$ & 0.30 \\
Unhealthy females & OCC & 1 & $0.65^{* *}$ \\
& SCC & $0.46^{* *}$ & $0.43^{* *}$ \\
\hline
\end{tabular}

"P $<0.01$

URA

SCC: Self-Concept Clarity; OCC: Obsessive-Compulsive concerns about Cleanliness; OCHI: Obsessive-Compulsive concerns about Harm and Injury

\section{Sive-Compulsive concerns about Harm \& Injury}

In Table 3, there was a significant and positive correlation between SCC and OCC ( $\mathrm{r}=-0.47, \mathrm{P}<0.01)$ and SCC and OCHI ( $\mathrm{r}=0.45, \mathrm{P}<0.01)$. OCC and OCHI were found with a significant correlation $(\mathrm{r}=-0.74, \mathrm{P}<0.01)$ in females with and without hormonal imbalance.

There was a significant positive correlation between $\mathrm{SCC}$ and $\mathrm{OCC}(\mathrm{r}=-0.33, \mathrm{P}<0.01)$ among healthy females. SCC and OCHI were not significantly correlated $(\mathrm{r}=0.297$, $\mathrm{P}>0.01$ ) in healthy females. Furthermore, OCC and OCHI were highly correlated $(\mathrm{r}=0.65, \mathrm{P}<0.01)$ in healthy females.

There was a significant positive correlation between SCC and OCC $(r=-0.460, \mathrm{P}<0.01), \mathrm{SCC}$ and OCHI were significantly correlated $(\mathrm{r}=0.431, \mathrm{P}<0.01)$, and $\mathrm{OCC}$ was strongly correlated with $\mathrm{OCHI}(\mathrm{r}=0.70, \mathrm{P}<0.01)$ in unhealthy females.
Table 4 indicates a significant difference $\mathrm{t}_{(208)}=-4.67$, $\mathrm{P}<0.0001$ among healthy $(31.87 \pm 8.16)$ and unhealthy (37.36 \pm 8.89$)$ females regarding SCC. Unhealthy females had a clearer self-concept than healthy females. Regarding OCC, there was a significant difference $\mathrm{t}_{(208)}=-6.98, \mathrm{P}<0.0001$ among healthy $(5.295 \pm 3.93)$ and unhealthy $(9.22 \pm 4.21)$ females. The level of OCHI was also higher $\mathrm{t}_{(208)}=-7.43, \mathrm{P}<0.0001$ in unhealthy females than healthy females.

\section{Summary of findings}

The study was conducted to psychologically assess the females with hormonal imbalance. Healthy females with an equal number were also included in the sample to make a comparison. The mean age of the overall sample was 21 years and the mean age of unhealthy females was 31 years. Also, $53 \%$ of the unhealthy females were unmarried. Most of the unhealthy females $(65.7 \%)$ were from the nuclear family system. It was found that the prevalence of the disease was high (42.9\%) in the upper class with a monthly income of more than eighty thousand.

Table 4. The difference in SCC, OCC, and OCHI among healthy and unhealthy females

\begin{tabular}{|c|c|c|c|c|c|c|}
\hline \multirow{2}{*}{ Variables } & \multicolumn{2}{|c|}{ Mean $\pm S D$} & \multirow{2}{*}{$\mathbf{t}$} & \multirow{2}{*}{ p } & \multicolumn{2}{|c|}{$\mathrm{Cl}$} \\
\hline & Healthy & Unhealthy & & & LL & UL \\
\hline SCC & $31.84 \pm 8.16$ & $37.36 \pm 8.89$ & -4.67 & 0.000 & -7.82 & -3.17 \\
\hline OCC & $5.295 \pm 3.93$ & $9.22 \pm 4.21$ & -6.98 & 0.000 & -5.03 & -2.81 \\
\hline $\mathrm{OCHI}$ & $6.171 \pm 4.49$ & $10.51 \pm 3.97$ & -7.43 & 0.000 & -5.49 & -3.19 \\
\hline
\end{tabular}

IRA

SCC: Self-Concept Clarity; OCC: Obsessive-Compulsive concerns about Cleanliness; OCHI: Obsessive-Compulsive concerns about Harm and Injury 
Levels of SCC, OCC, and OCHI were high in the overall sample as means of the scores were more than cut-off scores. By making a comparison between healthy and unhealthy females, it was found that unhealthy females had high levels of SCC, OCC, and OCHI than healthy females. A significant and positive correlation was found between OCC, OCHI, and SCC among females with and without hormonal imbalance.

\section{Discussion}

Comparison of healthy and unhealthy females revealed high levels of SCC, OCC, and OCHI among unhealthy females as the literature suggests that reproductive events can influence symptom severity of OCD.

Evidence of the impact of gonadal hormones during reproductive events on the neurotransmission in the brain that leads towards changes in the course of obsessive-compulsive tendencies was found in a critical review of literature conducted by Karpinksi et al. [14]. Another study provides evidence that pregnancy, childbirth, and menstruation are frequently associated with the onset of OCD [15].

High levels of SCC along with obsessive-compulsive tendencies and a positive significant correlation between them were found in this study. A study conducted on clinical samples with OCD and other anxiety disorders and a community control sample suggests high sensitivity of self-beliefs among patients with OCD [16].

An exacerbation of compulsive-like behaviors in mice was found after surgical removal of the ovaries, which mimics surgical menopause in humans and causes extreme hormonal changes due to a decrement of estrogen [17]. In a meta-analysis across six studies, the mean age of illness onset of OCD was between 14 and 21.2 years [18]. According to Miller et al., up to one-third of women report obsessive-compulsive behaviors in the early postpartum period [19].

In a study, initial assessment of OCD participants found significantly greater fear of self in individuals with personally repugnant obsessions (e.g. moral, sexual, religious, and aggressive symptoms) than in those with personally non-repugnant concerns (e.g. contamination, checking, ordering, and arranging; somatic obsessions) [20].

Self-esteem and OCD were negatively correlated in a study conducted on 65 patients at the clinic of Civil Hospital, Karachi, and 30 healthy controls [21]. Another study conducted on people with and without obsessivecompulsive symptoms suggests a negative correlation between SCC and obsessive-compulsive symptoms [22]. The reason for this observation may be due to the fact that the females with irregular hormonal fluctuations develop obsessive-compulsive tendencies because of the changes in the brain neurotransmission as mentioned earlier in the discussion and also people with obsessivecompulsive tendencies are most often sensitive to even unimportant affairs, and are even sensitive to themselves that might create clarity in their self-concept.

\section{Conclusion}

This study was done to examine the relationship between SCC, OCC, and OCHI. Another objective of the study was to identify the difference between SCC, OCC, and $\mathrm{OCHI}$ in healthy and unhealthy females. Therefore, a sample of 210 females, an equal number of healthy and unhealthy cases, was selected from different hospitals and the general population using the convenience sampling technique. Our findings declared that women with hormonal imbalance had high levels of SCC, OCC, and $\mathrm{OCHI}$ and there was a positive significant correlation between SCC, OCC, and OCHI among females with hormonal imbalance.

\section{Ethical Considerations}

\section{Compliance with ethical guidelines}

This study was conducted after approval from the local Ethics Committee at the Government College Women University (No.GCWUF/A.Psy/17/170).

\section{Funding}

This research did not receive any grant from funding agencies in the public, commercial, or non-profit sectors.

\section{Authors' contributions}

All authors equally contributed to preparing this article.

\section{Conflict of interest}

The authors declared no conflict of interest.

\section{References}

[1] Women in Balance Institute. Causes of hormone imbalance [Internet]. 2020 [Updated 26 October 2020]. Available from: https://womeninbalance.org/seventh-woman/causes/ 
[2] Karen Roth Nutrition. Physical and emotional effects of hormone imbalance [Internet]. 2011 [Updated 6 August 2011]. Available from: http://karenrothnutrition.com/physicaland-emotional -effects-of-hormone-imbalance/

[3] Rocky Mountain Women's Health. Female hormone imbalance: Causes and treatments [Internet]. 2015 [Updated 26 October 2015]. Available from: http://www.rockymountainwomenshealthcenter.com/blog/female-hormone-imbalance-causes-and-treatments/

[4] National Institute of Mental Health (NIH). Obsessive - compulsive disorder [Internet]. 2019 [Updated October 2019]. Available from: https://www.nimh.nih.gov/health/topics/ obsessive-compulsive-disorder-ocd/index.shtml

[5] Abramowitz JS, Deacon BJ, Olatunji BO, Wheaton MG, Berman NC, Losardo D, et al. Assessment of obsessive-compulsive symptom dimensions: Development and evaluation of the Dimensional Obsessive-Compulsive Scale. Psychol Assess. 2010; 22(1):180-98. [DOI:10.1037/a0018260] [PMID]

[6] Jiannine LM. An investigation of the relationship between physical fitness, self-concept, and sexual functioning. J Educ Health Promot. 2018; 7:57. [DOI:10.4103/jehp.jehp_157_17] [PMID] [PMCID]

[7] Castle D, Beilharz F, Phillips KA, Brakoulias V, Drummond LM, Hollander E, et al. Body dysmorphic disorder: A treatment synthesis and consensus on behalf of the International College of Obsessive-Compulsive Spectrum Disorders and the Obsessive Compulsive and Related Disorders Network of the European College of Neuropsychopharmacology. Int Clin Psychopharmacol. 2021; 36(2):61-75. [DOI:10.1097/ YIC.0000000000000342] [PMID] [PMCID]

[8] Fox EM. Mental illness identity: A look at the self, self-concept, and stigma resistance among those suffering from obsessive compulsive disorder [PhD. dissertation]. Kent: Kent State University; 2019. https://etd.ohiolink.edu/apexprod/ rws etd/send file/send?accession=kent1550592968807663\& disposition=inline

[9] Nitsche K, Moritz S, Jelinek L. Prenatal sex hormones and finger length: Digit ratio (2D: 4D) as a biological marker of early developmental processes in patients with ObsessiveCompulsive Disorder (OCD). J Obsessive Compuls Relat Disord. 2020; 25:100525. [DOI:10.1016/j.jocrd.2020.100525]

[10] Psychology Research and Reference. Self-concept clarity [Internet]. 2020 [Updated 30 October 2020]. Available from: https://psychology.iresearchnet.com/social-psychology/ self/self-concept-clarity/

[11] Vulink NCC, Denys D, Bus L, Westenberg HGM. Female hormones affect symptom severity in obsessive-compulsive disorder. Int Clin Psychopharmacol. 2006; 21(3):171-5. [DOI:10.1097/01.yic.0000199454.62423.99] [PMID]

[12] Campbell JD, Trapnell PD, Heine SJ, Katz IM, Lavallee LF, Lehman DR. Self-concept clarity: Measurement, personality correlates, and cultural boundaries. J Personal Soc Psychol. 1996; 70(1):141-56. [DOI:10.1037// 0022-3514.70.1.141]

[13] Abramowitz JS, Deacon BJ, Olatunji BO, Wheaton MG, Berman NC, Losardo D, et al. Assessment of obsessive-compulsive symptom dimensions: Development and evaluation of the Dimensional Obsessive-Compulsive. Scale Psychol. Assess. 2010; 22(1):180-9. [DOI:10.1037/a0018260]
[14] Karpinski M, Mattina GF, Steiner M. Effect of gonadal hormones on neurotransmitters implicated in the pathophysiology of obsessive-compulsive disorder: A critical review. Neuroendocrinology. 2017; 105(1):1-6. [DOI:10.1159/000453664] [PMID]

[15] Forray A, Focseneanu M, Pittman B, McDougle CJ, Epperson $\mathrm{CN}$. Onset and exacerbation of obsessive-compulsive disorder in pregnancy and the postpartum period. Int Clin Psychopharmacol. 2010; 71(8):1061-8. [DOI:10.4088/ JCP.09m05381blu] [PMID] [PMCID]

[16] Doron G, Moulding R, Kyrios M, Nedeljkovic M. Sensitivity of self-beliefs in Obsessive Compulsive Disorder. Depress Anxiety. 2008; 25(10):874-84. [DOI:10.1002/da.20369] [PMID]

[17] Mitra S, Bastos CP, Bates K, Pereira GS, Bult-Ito A. Ovarian sex hormones modulate compulsive, affective and cognitive functions in a non-induced mouse model of obsessivecompulsive disorder. Front Behav Neurosci. 2016; 10:215. [DOI:10.3389/fnbeh.2016.00215] [PMID] [PMCID]

[18] Frare F, Perugi G, Ruffolo G, Toni C. Obsessive-Compulsive Disorder and body dysmorphic disorder: A comparison of clinical features. Eur Psychiatry. 2004; 19(5):292-8. [DOI:10.1016/j.eurpsy.2004.04.014] [PMID]

[19] Miller ES, Hoxha D, Wisner KL, Gossett DR. The impact of perinatal depression on the evolution of anxiety and obsessive-compulsive symptoms. Arch Womens Ment Health. 2015; 18(3):457-61. [DOI:10.1007/s00737-014-0476-x] [PMID] [PMCID]

[20] Aardema F, Moulding R, Melli G, Radomsky AS, Doron G, Audet JS, et al. The role of feared possible selves in obsessivecompulsive and related disorders: A comparative analysis of a core cognitive self-construct in clinical samples. Clin Psychol Psychother. 2018; 25(1):e19-29 [DOI:10.1002/cpp.2121] [PMID]

[21] Rahman RU, Husain N. Self-esteem in Obsessive Compulsive Disorder. Eur Psychiatry. 2009; 24(S1):1. [DOI:10.1016/ S0924-9338(09)71269-6]

[22] May E. Attachment security, self-concept clarity and beliefs in Obsessive-Compulsive Disorder [PhD dissertation]. Hatfield: University of Hertfordshire; 2007. https://uhra.herts. ac.uk/handle/2299/853 
This Page Intentionally Left Blank 